\title{
Path Profile for Terrestrial Line of Site Microwave Link in the C-Band
}

\author{
Enyenihi Henry Johnson ${ }^{1}$, Okoye O. Jude ${ }^{2}$, Obinwa Christian Amaefule ${ }^{3}$ \\ ${ }^{1}$ Department of Electrical/Electronic Engineering, Akwa Ibom State University, Mkpat Enin, Nigeria \\ ${ }^{2}$ Department of Electrical/Electronic and Computer Engineering, University of Uyo, Uyo, Nigeria \\ ${ }^{3}$ Department of Electrical Engineering, Imo State University (IMSU), Owerri, Nigeria
}

Email address:

gentlejayy@yahoo.com (E. H. Johnson)

To cite this article:

Enyenihi Henry Johnson, Okoye O. Jude, Obinwa Christian Amaefule. Path Profile for Terrestrial Line of Site Microwave Link in the C-Band. International Journal of Information and Communication Sciences. Vol. 2, No. 2, 2017, pp. 15-23. doi: 10.11648/j.ijics.20170202.11

Received: October 16, 2016; Accepted: December 27, 2016; Published: April 26, 2017

\begin{abstract}
In this paper, development of path profile for $6 \mathrm{GHz}$ C-band terrestrial line-of-site microwave link is presented. The path (elevation) profile data set is obtained using Geocontext online elevation software. With the path profile, the minimum antenna elevation and the minimum antenna mast heights for effective line of site installation are determined. According to the results, when path inclination is greater than zero, antenna elevation is $105.873 \mathrm{~m}$ and $88.528 \mathrm{~m}$ at the transmitter and receiver respectively, with antenna mast height of $36.712 \mathrm{~m}$ at both the transmitter and the receiver and critical clearance of $4.787 \mathrm{~m}$ at a distance of $1897.626 \mathrm{~m}$ from the transmitter. However, when path inclination is equal to zero, antenna elevation is $88.528 \mathrm{~m}$ at both the transmitter and receiver with antenna mast height of $19.367 \mathrm{~m}$ and $36.712 \mathrm{~m}$ at the transmitter and receiver respectively. In this case, the critical clearance is $0 \mathrm{~m}$ (zero meter) at a distance of $686.641 \mathrm{~m}$ from the transmitter.
\end{abstract}

Keywords: Path Profile, Microwave Link, Line-of-Site, C-Band, Path Inclination, Fresnel Zone, Earth Bulge

\section{Introduction}

At high frequencies such as the microwave frequencies, adequate planning is required to ensure line-of-site between the antennas at two distant communication link endpoints [1-5]. In this case, some factors must be taken into consideration in order to ensure clear line-of-sight; among the factors are, the earth curvature, the Fresnel Zone clearance, the atmospheric refraction and possible obstacles on the path of the communication link [6-9]. However, "in order to determine tower heights for suitable path clearance, a pat profile must be plotted" [10-12].

According to Standard (1996), path profile is a graphic representation of the physical features of signal propagation path; the path profile contains both endpoints of the path and shows the elevations in the vertical plane of points between the endpoints. The path profile also shows the Earth surface along with buildings, trees, and other features that may block the radio signal [13]. Importantly, proper planning of microwave and cellular path profile can help network planners to determine accurate tower heights for the antenna in order to achieve Line-of-Sight (LOS) clearance of the first Fresnel
Zone or Fresnel Radius from obstacles that are along the radio propagation path and this will improve the Quality of Service (QoS) delivery of deployed systems [1, 14-15].

In this paper, approach for generating and plotting the path profile for terrestrial line of site microwave link in presented. In order to generate the path profile for terrestrial line of site microwave link, the elevation data along the signal path is required. The elevation data is used in conjunction with the signal frequency to generate and plot the various components of the path profile. The components of the path profile includes amongst others; elevation profile, earth bulge, Fresnel zone ellipsoid, minimum transmitter antenna height, minimum receiver antenna height and the location of the critical point for maintaining clear line of site. Sample path profile data set for a $\mathrm{C}$-band link at $6 \mathrm{GHz}$ is generated and plotted for two cases, when the path inclination is equal to zero and when the path inclination is greater than zero. The signal path (or link) elevation profile (that is, elevation and distance) are obtained using Geocontext Online Elevation software [16]. With the path profile data and graph plots, the minimum antenna elevation and the minimum antenna mast heights for effective line of site installation are determined. The path profile ideas presented in this paper is very useful for 
terrestrial line of site microwave network designers and researchers.

\section{Methodology}

The following steps are used in generating the path profile for a C-band terrestrial line of site microwave link between University of Uyo Town Campus at Ipka Road and the Main Campus of University of Uyo which is at Use Offort:.

Step 1: The Signal Frequency

The radius of the Fresnel Zone is a functions of frequency. As such, in this study the $6 \mathrm{GHz}$ (in the C-Band) is considered.
Step 2: The Location (Longitude and Latitude) Of The Transmitter and The Receiver

Let $L O N G_{t x}$ and $L A T_{t x}$ be the longitude and attitude of the coordinates of the Let $L O N G_{r x}$ and $L A T_{r x}$ be the longitude and attitude of the coordinates of the receiver respectively. transmitter respectively.

University of Uyo

Step 3: The Distance Between The Transmitter and The Receiver

The path length (or distance), $\boldsymbol{d}$ in $\mathrm{Km}$ between the transmitter and receiver is determined by using the Haversine formula and the coordinates (longitude and the latitude) of the transmitter and receiver. The Haversine formula is given as:

$$
d=2 R\left\{\sqrt[2]{\sin \left(\frac{L A T_{r x}-L A T_{t x}}{2}\right)^{2}+\cos \left(L A T_{r x}\right) \cos \left(L A T_{t x}\right) \sin \left(\frac{L O N G_{r x}-L O N G_{t x}}{2}\right)^{2}}\right\}
$$

Where LAT in Radians $=\frac{(\text { LAT in Degrees } * 3.142)}{180}$

$$
\text { LONG in Radians }=\frac{(\text { LONG in Degrees } * 3.142)}{180}
$$

Where

- $L A T_{t x}$ and $L A T_{r x}$ are the latitude of the coordinates of pointl and point 2 respectively

- $L O N G_{t x}$ and $L O N G_{r x}$ are the longitude of the coordinates of point 1 and point $x$ respectively

- $\mathrm{R}=$ radius of the earth $=6371 \mathrm{~km}$. $\mathrm{R}$ varies from $6356.752 \mathrm{~km}$ at the poles to $6378.137 \mathrm{~km}$ at the equator.

- $d=$ the distance in Km between the two coordinates

Step 4: The Elevation Data and the Elevation Profile Between The Transmitter and Receiver

The Elevation Data set for the given location is generated using an Geocontext Online Elevation software [15].

The elevation data is generated by entering the longitude and latitude of the transmitter $\left(L O N G_{t x}\right.$ and $\left.L A T_{t x}\right)$ and the longitude and latitude of the receiver $\left(L O N G_{r x}\right.$ and $\left.L A T_{r x}\right)$ into the source and destination coordinates textboxes on the Geocontext Online Elevation software. The elevation data set generated by the Geocontext Online Elevation software [15] includes:

i. Points specified by their longitudes and latitudes,

ii. The start point at the transmitter (transmitter location is the first point)

iii. The end or the last point at the receiver (receiver location is the last point)

iv. Distance of each of the points from the starting point's longitude and latitude

v. The elevation at each point above sea level as the reference plane.

Step 5: The Earth Bulge

The formula for calculating the Earth bulge at a distance $d_{1}$ from the transmitter and distance $d_{2}$ from the receiver is given as follows:

$$
H_{b(x)}=\frac{1000\left(d_{1}\right)\left(d_{2}\right)}{8\left(E_{r}\right)}
$$

where,
- $H_{b(x)}=$ Height difference of Earth's Curvature at the point $\mathrm{x}$ between the transmitter and the receiver $(\mathrm{m})$

- $d_{1}=$ Distance between the point and the transmitter $(\mathrm{km})$

- $d_{2}=$ Distance between the point and the receiver $(\mathrm{km})$

- $E_{r}=$ Effe 6 tive Radius of Earth $(\mathrm{km})$ Note: Usually taken as $\overline{3}$ (1.333 rec.)actual radius to account for atmospheric refraction i.e. $E_{r}=8,504 \mathrm{~km}$

Step 6: The Radius of the First Fresnel Zone

The radius of the $k^{\text {th }}$ Fresnel zone at point $\mathrm{x}$ is given as;

$$
r_{f k(x)}=\sqrt[2]{\left(\frac{k(\kappa)\left(d_{1}\right)\left(d_{2}\right)}{\left(d_{1}\right)+\left(d_{2}\right)}\right)}=\sqrt[2]{\left(\frac{k(\kappa)\left(d_{1}\right)\left(d_{2}\right)}{d}\right)}
$$

where $\mathrm{k}=1,2,3, \ldots$

$r_{f k(x)}$ is the radius of the $k^{t h}$ Fresnel zone at point $\mathrm{x}$.

$d_{1}$ is the distance of the point from the transmitter

$d_{2}$ is the distance of the point from the receiver

$d$ is the distance between the transmitter and the receiver where

$$
d=d_{1}+d_{2}
$$

$\Lambda$ is the wavelength of the signal, where;

$$
\Lambda=\frac{c}{f}
$$

where,

- $\mathrm{C}=$ Speed of light in a vacuum $\left(3 \times 10^{8} \mathrm{~ms}^{-1}\right)$

- $\mathrm{d}=$ Total Distance $(\mathrm{m})$

- $\mathrm{f}=$ Signal frequency $(\mathrm{Hz})$

Step 7: The Maximum Height Of Obstacle In The Terrain

The maximum height of obstacle $\left(H_{\text {obstacle }}(x)\right)$ is estimated from the knowledge of the terrain. In this research, the terrain within which the link is located is in Uyo metropolis. The obstacles expected in the terrain are mainly buildings. The buildings within the signal path in Uyo are mainly two storey buildings. As such, the obstacle height is estimated as 10 meters.

Step 8: The Minimum Height of Antenna For Line of Sight Installation

The theoretical minimum height of antenna $\left(H_{\text {antenna(minimum })}\right)$ for line of sight installation is calculated 
with respect to elevation, radius of first Fresnel zone, height of obstacle and earth bulge, as follows:

$$
H_{\text {antenna }(\text { minimum })}=\operatorname{maximum}_{x=1,2,3, \ldots n_{e}}\left(E_{x}+r_{f k(x)}+H_{b(x)}+H_{\text {obstacle }(x)}\right)
$$

where

$\mathrm{r}_{\mathrm{fk}(\mathrm{x})}$ is the radius of the $\mathrm{k}^{\text {th }}$ Fresnel zone at point $\mathrm{x}$.

$\mathrm{H}_{\mathrm{b}(\mathrm{x})}=$ Height difference of Earth's Curvature at the point $\mathrm{x}$ between the transmitter and the receiver $(\mathrm{m})$

$\mathrm{H}_{\text {obstacle(x) }}$ is the maximum height of obstacle

$E_{X}$ is the elevation in meter at point $x$

$$
H_{\text {effant (minimum) }}=H_{\text {antenna(minimum })}-\operatorname{minimum}_{x=1,2,3, \ldots n_{e}}\left(E_{t x}, E_{r x}\right)
$$

Let $H_{t x}$ be the Height of Transmitter antenna and let $H_{r x}$ be the Height of Receiver antenna, then

$$
\begin{aligned}
& H_{t x}=E_{t x}+H_{\text {effant(minimum) }} \\
& H_{r x}=E_{r x}+H_{\text {effant(minimum) }}
\end{aligned}
$$

Step 10: Generate the Fresnel Ellipsoid

The Fresnel ellipsoid if formed around the centre of the Fresnel zone. In order to generate the Fresnel Ellipsoid, the centre line (line-of-sight) through the Fresnel zone is first generated. Then the radius of the first Fresnel zone is added to the value of the elevation at the centre line of the Fresnel zone (for the upper part of Fresnel ellipsoid) and subtracted from the value of the elevation at the centre line of the Fresnel zone (for the lower part of Fresnel ellipsoid). Fresnel Zone

Let the elevation at the transmitter is $E_{r x}$ and the Elevation at the receiver be $E_{r x}$, respectively.
Step 11: The Centre Line (Line-Of-Sight) Through The $d_{t x}$ and the distance of the receiver from the transmitter be $d_{r x}$.

Let the gradient $\left(m_{t x r x}\right)$ of the line linking the transmitter and the receiver be defined as;

$$
m_{t x r x}=\frac{\left(E_{r x}-E_{t x}\right)}{\left(d_{r x}-d_{r x}\right)}
$$

The equation for the transmitter to receiver line that passes through the point $\left(d_{x}, E_{x f}\right)$ is given as:

$$
\begin{gathered}
\frac{\left(E_{x f}-E_{t x}\right)}{\left(d_{x}-d_{t x}\right)}=\frac{\left(E_{r x}-E_{t x}\right)}{\left(d_{r x}-d_{t x}\right)}=m_{t x r x} \\
E_{x f}-E_{t x}=m_{t x r x}\left(d_{x}-d_{t x}\right) \\
E_{x f}=m_{t x r x}\left(d_{x}-d_{t x}\right)+E_{t x}
\end{gathered}
$$

Now, $d_{t x}=0 \mathrm{~m}$ and $d_{r x}=6379.51952869827 \mathrm{~m}$. Also, $E_{t x}=69.16137695 \mathrm{~m}$ and $E_{r x}=51.8163147 \mathrm{~m}$.
Let the distance of the transmitter from the transmitter is

$$
\begin{aligned}
& \qquad m_{t x r x}=\frac{\left(E_{r x}-E_{t x}\right)}{\left(d_{r x}-d_{r x}\right)}=\frac{(51.8163147-69.16137695)}{(6379.51952869827-0)}=-0.00271887 \\
& E_{x f}=-0.00271887\left(d_{x}-0\right)+69.16137695 \quad(17) \quad \text { of the Fresnel zone defined in } \\
& \text { elevation for the upper part } \\
& \text { point } \mathrm{x} \text { and let } E_{f d(x)} \text { be the e } \\
& E_{x f}=-0.00271887 d_{x}+69.16137695
\end{aligned}
$$

of the Fresnel zone defined in equation 3.26. Let $E_{f u(x)}$ be the elevation for the upper part of the first Fresnel ellipsoid at point x and let $E_{f d(x)}$ be the elevation for the lower part of the first Fresnel ellipsoid at point $\mathrm{x}$, then;

Where $\mathrm{r}_{\mathrm{fk}(\mathrm{x})}$ is the radius of the $\mathrm{k}^{\text {th }}$ Fresnel zone at point $\mathrm{x}$.

Step 13: The Path Inclination

Path inclination $\varepsilon_{p}$ is given as follows;

$$
\varepsilon_{p}=\frac{\left|H_{t x}-H_{r x}\right|}{d}
$$

where $\mathrm{d}$ (in $\mathrm{Km}$ ) is the distance between the transmitter and the receiver while $H_{t x}$ and $H_{r x}$ are in meters are the height of the transmitter and the receiver respectively.

\section{Results and Discussions}

A sample microwave link is used to demonstrate the effectiveness of the path profile algorithm presented in paper. The path profile data set and graph plots are presented for two cases; when the path inclination is equal to zero and when the path inclination is greater than zero. The results for the sample path profile studied are presented in this section 4 .

Step 1: The Signal Frequency

In this study, the C-band is considered and the frequency selected is $6 \mathrm{GHz}$.

Step 2: The Location (Longitude and Latitude) Of The 
Transmitter and The Receiver

The transmitter is located at University of Uyo Town Campus at Ipka Road. Then, in Figure 1. $L O N G_{t x}=$ 7.919108 and $L A T_{t x}=5.042362$. Also, the receiver is located at the Main Campus of University of Uyo which is at Use Offort.. Then, in Figure 1. $L O N G_{r x}=7.976615$ and $L A T_{r x}=5.040823$.

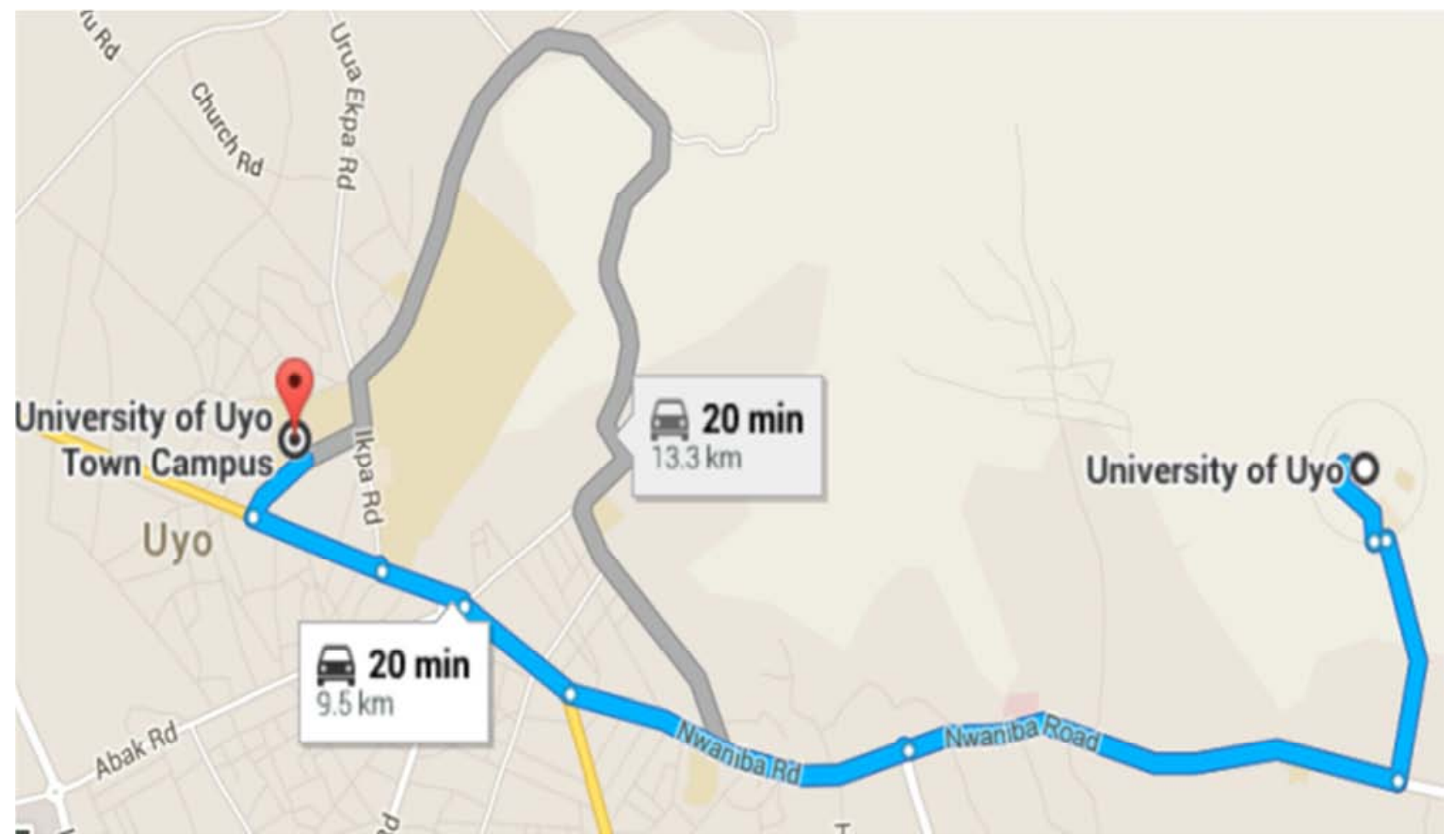

Figure 1. Screenshot of The Google Map View Of The Location Of The Transmitter at University of Uyo Town Campus and The Receiver at the Main Campus of.

Step 4: The Elevation Data and The Elevation Profile Between The Transmitter and Receiver

Some portions of the 512 records in the elevation dataset for the given transmitter and receiver location are given a in table 1. The dataset is generated using a Geocontext Online Elevation [15]. As shown in Figure 1, the transmitter is located at University of Uyo Town Campus, Ikpa Road with longitude of 7.919108 and latitude of 5.042362 while the receiver located at the Main Campus of University of Uyo, Use Offort at longitude of 7.976615 and latitude of 5.040823. The elevation profile plot for all the 512 data points in the full dataset is given in Figure 2. From Table 1 and Figure 2, the elevation at the transmitter is $69.161 \mathrm{~m}$ (Column 5, Data Point Number 1) whereas the elevation at the receiver is $51.816 \mathrm{~m}$ (Column 5, Data Point Number 512).

Table 1. Selected Portion of the 512 Data Points In The Elevation Profile Dataset.

\begin{tabular}{|c|c|c|c|c|c|c|}
\hline Column 1 & Column 2 & Column 3 & Column 4 & Column 5 & Column 6 & Column 7 \\
\hline Data Point Number & Latitude & Longitude & Distance (m) & Elevation (m) & Distance in Mile & Elevation (ft) \\
\hline 1 & 5.04236 & 7.91911 & 0.000 & 69.161 & 0.0000 & 226.907 \\
\hline 32 & 5.042266719 & 7.922598873 & 387.016 & 69.183 & 0.2405 & 226.979 \\
\hline 64 & 5.04217041 & 7.926200289 & 786.516 & 68.964 & 0.4887 & 226.260 \\
\hline 96 & 5.042074081 & 7.929801704 & 1186.016 & 31.262 & 0.7370 & 102.565 \\
\hline 128 & 5.041977732 & 7.933403117 & 1585.517 & 56.770 & 0.9852 & 186.254 \\
\hline 192 & 5.041784975 & 7.940605942 & 2384.517 & 58.895 & 1.4817 & 193.224 \\
\hline 256 & 5.041592138 & 7.947808762 & 3183.518 & 43.500 & 1.9781 & 142.717 \\
\hline 288 & 5.041495691 & 7.951410171 & 3583.018 & 37.450 & 2.2264 & 122.866 \\
\hline 320 & 5.041399223 & 7.955011578 & 3982.518 & 34.161 & 2.4746 & 112.077 \\
\hline 352 & 5.041302735 & 7.958612984 & 4382.018 & 49.212 & 2.7229 & 161.458 \\
\hline 384 & 5.041206228 & 7.96221439 & 4781.519 & 56.030 & 2.9711 & 183.826 \\
\hline 416 & 5.041109701 & 7.965815794 & 5181.019 & 50.308 & 3.2193 & 165.054 \\
\hline 448 & 5.041013154 & 7.969417197 & 5580.519 & 52.172 & 3.4676 & 171.169 \\
\hline 480 & 5.040916587 & 7.973018599 & 5980.019 & 51.368 & 3.7158 & 168.531 \\
\hline
\end{tabular}




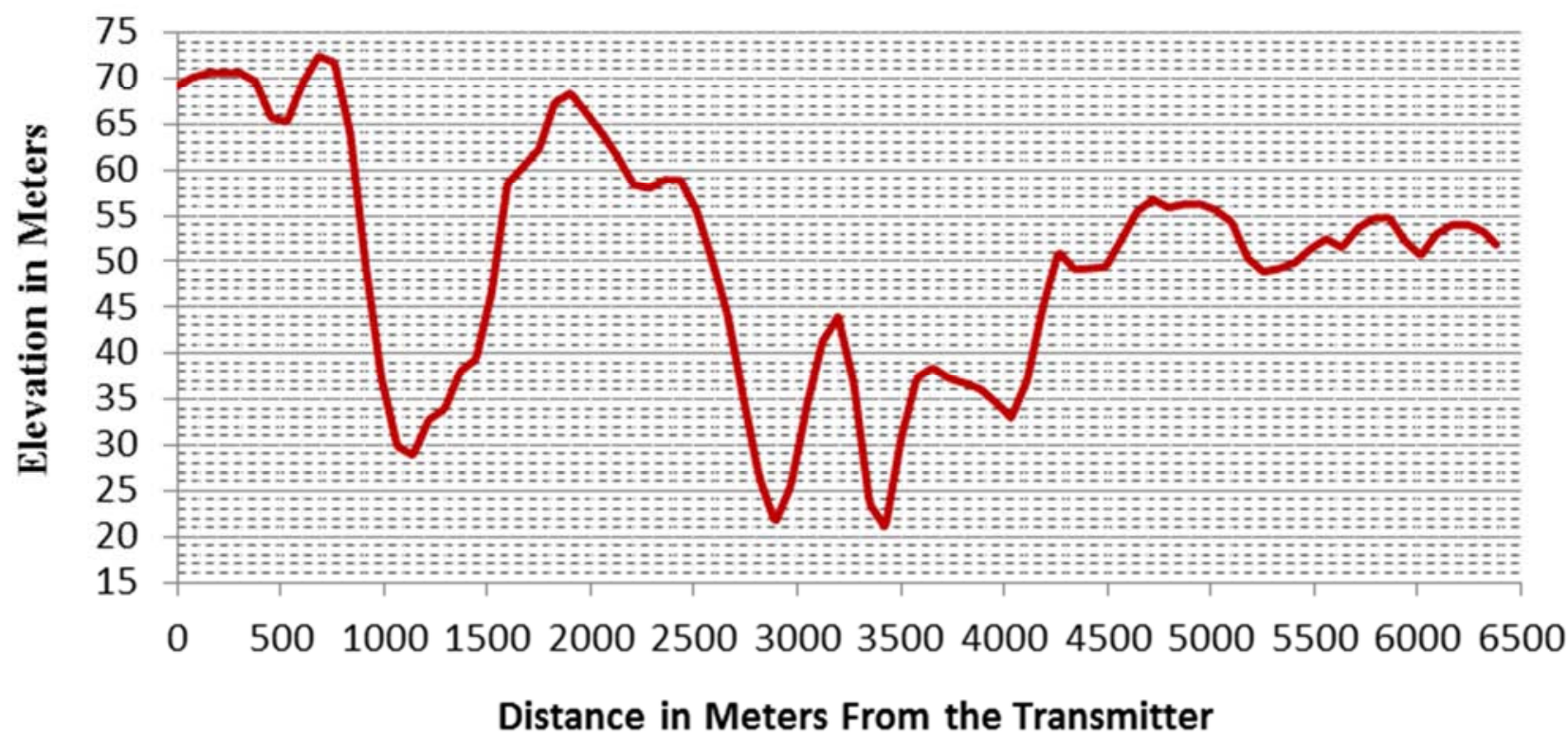

Figure 2. Elevation Profile (Elevation Versus Distance).

Some portions of the 512 records in the complete path profile dataset for the given transmitter and receiver location and microwave signal at $6 \mathrm{GHz}$ are given in Table 1 . The path profile plot for all the 512 data points in the full path profile dataset is given in Figure 3. For Path Inclination $(\varepsilon p)>0$ and in Figure 4. For Path Inclination $(\varepsilon p)=0$.

Table 2. Selected Portions of the 512 Data Points in the Path Profile Dataset for 6 GHz Signal For Path Inclination ( $\varepsilon p)=0$ and Path Inclination ( $\varepsilon p)>0$.

\begin{tabular}{|c|c|c|c|c|c|}
\hline Column 1 & Column 2 & Column 3 & Column 4 & Column 5 & Column 6 \\
\hline $\begin{array}{l}\text { Data Point } \\
\text { Number }\end{array}$ & $\begin{array}{l}\text { Distance }(m) \text { from the } \\
\text { Transmitter }\end{array}$ & Elevation (m) & $\begin{array}{l}\text { Radius of the First } \\
\text { Fresnel Zone (in Meters) }\end{array}$ & $\begin{array}{l}\text { Earth Bulge (in } \\
\text { Meters) }\end{array}$ & $\begin{array}{l}\text { Line Of Site Elevation } \\
(\varepsilon p>0)\end{array}$ \\
\hline 1 (Transmitter) & 0 & 69.161 & 0 & 0 & 105.873 \\
\hline 32 & 387.016 & 69.183 & 4.263 & 0.341 & 104.821 \\
\hline 56 & 686.641 & 72.419 & 5.535 & 0.575 & 104.006 \\
\hline 128 & 1585.517 & 56.77 & 7.718 & 1.117 & 101.562 \\
\hline 153 & 1897.626 & 68.348 & 8.164 & 1.25 & 100.714 \\
\hline 192 & 2384.517 & 58.895 & 8.641 & 1.4 & 99.39 \\
\hline 224 & 2784.017 & 29.95 & 8.857 & 1.471 & 98.304 \\
\hline 250 & 3108.611 & 40.23 & 8.927 & 1.495 & 97.421 \\
\hline 251 & 3121.096 & 41.313 & 8.928 & 1.495 & 97.387 \\
\hline 256 & 3183.518 & 43.5 & 8.93 & 1.494 & 97.218 \\
\hline 288 & 3583.018 & 37.45 & 8.862 & 1.473 & 96.132 \\
\hline 320 & 3982.518 & 34.161 & 8.65 & 1.403 & 95.045 \\
\hline 384 & 4781.519 & 56.03 & 7.739 & 1.123 & 92.873 \\
\hline 416 & 5181.019 & 50.308 & 6.976 & 0.913 & 91.787 \\
\hline 448 & 5580.519 & 52.172 & 5.912 & 0.655 & 90.701 \\
\hline 480 & 5980.019 & 51.368 & 4.327 & 0.351 & 89.614 \\
\hline 512 (Receiver) & 6379.52 & 51.816 & 0 & 0 & 88.528 \\
\hline
\end{tabular}

Table 2. Continue.

\begin{tabular}{llll}
\hline Column 1 & Column 7 & Column 8 & Column 9 \\
\hline \multirow{2}{*}{ Data Point Number } & $\begin{array}{l}\text { Line Of Site } \\
\text { Elevation }(\boldsymbol{\varepsilon p}=\mathbf{0})\end{array}$ & $\begin{array}{l}\text { Clearance Distance (in meters) } \\
\text { and Fresnel Zone }(\boldsymbol{\varepsilon p}>\mathbf{0})\end{array}$ & $\begin{array}{l}\text { Clearance Distance (in meters) Between } \\
\text { Obstacle and Fresnel Zone }(\boldsymbol{\varepsilon p}=\mathbf{0})\end{array}$ \\
\hline 1 (Transmitter) & 88.528 & 26.712 & 9.367 \\
32 & 88.528 & 16.77 & 4.741 \\
56 & 88.528 & 9.943 & 0 \\
128 & 88.528 & 18.238 & 12.922 \\
153 & 88.528 & 4.787 & 0.766 \\
160 & 88.528 & 6.653 & 2.974 \\
192 & 88.528 & 11.814 & 9.593 \\
224 & 88.528 & 39.167 & 38.249 \\
250 & 88.528 & 27.843 & 27.877 \\
\hline
\end{tabular}




\begin{tabular}{llll}
\hline Column 1 & Column 7 & Column 8 & Column 9 \\
\hline \multirow{2}{*}{ Data Point Number } & $\begin{array}{l}\text { Line Of Site } \\
\text { Elevation }(\boldsymbol{\varepsilon p}=\mathbf{0})\end{array}$ & $\begin{array}{l}\text { Clearance Distance (in meters) Between Obstacle } \\
\text { and Fresnel Zone }(\boldsymbol{\varepsilon p}>\mathbf{0})\end{array}$ & $\begin{array}{l}\text { Clearance Distance (in meters) Between } \\
\text { Obstacle and Fresnel Zone ( } \mathbf{\varepsilon p}=\mathbf{0})\end{array}$ \\
\hline 251 & 88.528 & 26.724 & 26.792 \\
256 & 88.528 & 24.362 & 24.602 \\
288 & 88.528 & 29.485 & 30.744 \\
320 & 88.528 & 32.182 & 34.314 \\
352 & 88.528 & 16.895 & 19.747 \\
384 & 88.528 & 10.243 & 13.636 \\
416 & 88.528 & 16.613 & 20.331 \\
448 & 88.528 & 16.05 & 19.789 \\
480 & 88.528 & 19.241 & 22.482 \\
512 (Receiver) & 88.528 & 26.712 & 26.712 \\
\hline
\end{tabular}

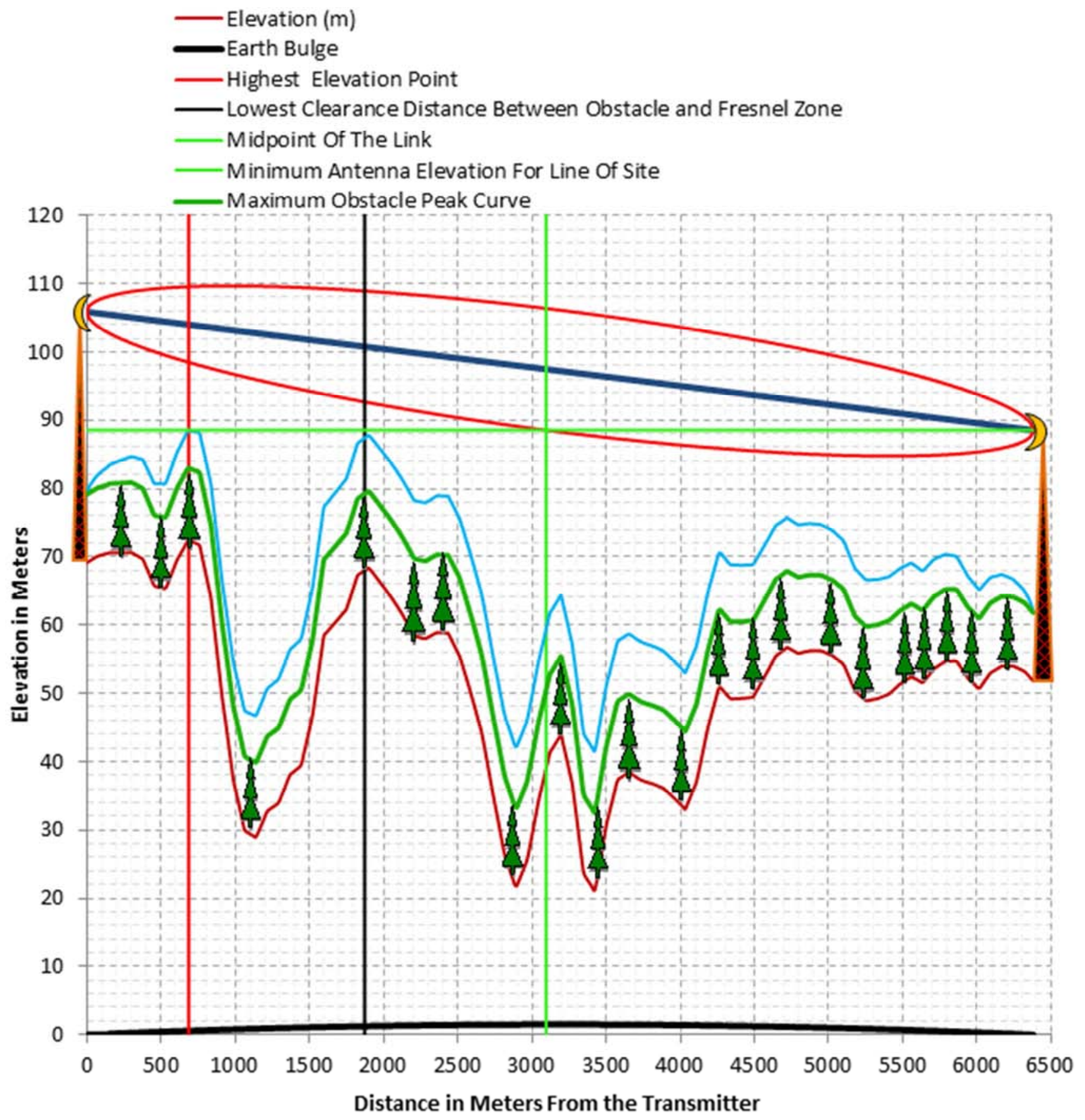

Figure 3. Complete Path Profile: Elevation Versus Distance For $6 \mathrm{GHz}$ Signal and With Path inclination Greater Than Zero. 
According to Table 2, when the path inclination is $(\varepsilon p)>0$, the line of site is a line with negative gradient, sloping from line of site elevation of $105.873 \mathrm{~m}$ (column 6 and row Data Point Number 1 of table 2) at the transmitter, down to line of site elevation of $88.528 \mathrm{~m}$ (column 6 and row Data Point Number 512 of table 2) at the receiver. Furthermore, in column 8 and column 2 of row Data Point Number 153 in table 2, the critical point for line of site has $4.787 \mathrm{~m}$ clearance distance (in meters) between obstacle and the first Fresnel zone and it is located at a distance of $1897.626 \mathrm{~m}$ from the transmitter.

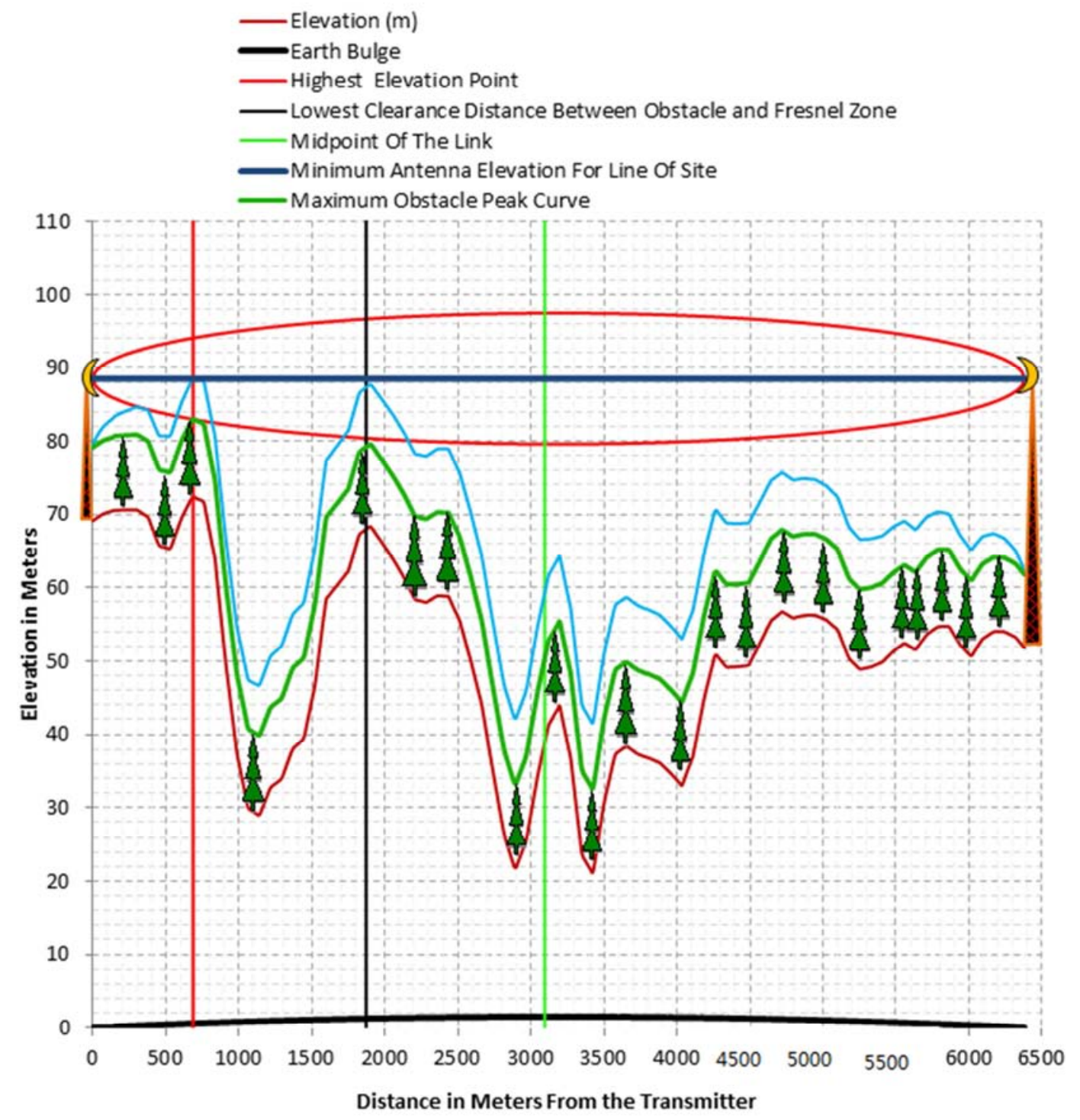

Figure 4. Complete Path Profile : Elevation Versus Distance For 6GHz Signal and With Zero Path inclination.

The critical point for line of site is indicated as the vertical black line in Figure 3. The clearance distance between obstacle and the first Fresnel zone at the link midpoint (in column 2 and column 8 of row Data Point Number 250 and 251 in table 2) is above $27 \mathrm{~m}$. However, the earth bulge is highest at the link midpoint with earth bulge of about $1.495 \mathrm{~m}$ (column 5 of row Data Point Number 250 and 251 in table 2). The link midpoint is indicated as the vertical green line in Figure 3 and Figure 4.

On the other hand, according to Table 2, when the path inclination is $(\varepsilon p)=0$, the line of site is a horizontal line at line of site elevation of $88.528 \mathrm{~m}$ (column 7 and row Data Point Number 1 of table 2) at the transmitter and at the receiver as well (column 7 and row Data Point Number 512 of table 2).
Furthermore, in column 9 and column 2 of row Data Point Number 56 in table 2, the critical point for line of site has $0 \mathrm{~m}$ clearance distance (in meters) between obstacle and the first Fresnel zone and it is located at a distance of $686.641 \mathrm{~m}$ from the transmitter. The critical point for line of site is indicated as the vertical red line in Figure 4. The clearance distance between obstacle and the first Fresnel zone at the link midpoint (in column 2 and column 9 of row Data Point Number 250 and 251 in table 2) is above $27 \mathrm{~m}$.

When Path Inclination $(\varepsilon p)>0$, the transmitter and receiver antenna elevation and mast heights can be determined from the data in table 2 as follows;

Transmitter Antenna Elevation = Line of Site Elevation at the Transmitter $=105.873 \mathrm{~m}$ 
Transmitter Antenna Mast Height $=$ Transmitter Antenna Elevation - Elevation at the Transmitter Location $=105.873 \mathrm{~m}$

$$
-69.161 \mathrm{~m}=36.712 \mathrm{~m}
$$

Receiver Antenna Elevation $=$ Line of Site Elevation at the

$$
\text { Receiver }=88.528 \mathrm{~m}
$$

Receiver Antenna Mast Height $=$ Receiver Antenna Elevation - Elevation at the Receiver Location $=88.528 \mathrm{~m}-51.816 \mathrm{~m}=$ $36.712 \mathrm{~m}$

Similarly, when Path Inclination $(\varepsilon p)=0$, the transmitter

and receiver antenna elevation and mast heights can be determined from the data in table 2 as follows;

Transmitter Antenna Elevation $=$ Line of Site Elevation at the Transmitter $=88.528 \mathrm{~m}$

Transmitter Antenna Mast Height $=$ Transmitter Antenna Elevation - Elevation at the Transmitter Location $=88.528 \mathrm{~m}$ $69.161 \mathrm{~m}=19.367 \mathrm{~m}$.

Receiver Antenna Elevation $=$ Line of Site Elevation at the Receiver $=88.528 \mathrm{~m}$

Receiver Antenna Mast Height $=$ Receiver Antenna Elevation -

Elevation at the Receiver Location $=88.528 \mathrm{~m}-51.816 \mathrm{~m}=36.712 \mathrm{~m}$.

Table 3. The Transmitter and Receiver Antenna Elevation and Mast Heights.

\begin{tabular}{llll}
\hline & $\begin{array}{l}\text { Elevation at The Transmitter } \\
\text { Location }\end{array}$ & $\begin{array}{l}\text { Transmitter Antenna Mast } \\
\text { Height }\end{array}$ & $\begin{array}{l}\text { Line Of Site Elevation at the Transmitter (Or } \\
\text { Transmitter Antenna Elevation) }\end{array}$ \\
\hline Path Inclination $(\varepsilon p)>0$ & $69.161 \mathrm{~m}$ & $36.712 \mathrm{~m}$ & $105.873 \mathrm{~m}$ \\
Path Inclination $(\varepsilon p)=0$ & $69.161 \mathrm{~m}$ & $19.367 \mathrm{~m}$ & $88.528 \mathrm{~m}$ \\
\hline
\end{tabular}

Table 3. Continue.

\begin{tabular}{llll}
\hline & $\begin{array}{l}\text { Elevation at The Receiver } \\
\text { Location }\end{array}$ & $\begin{array}{l}\text { Receiver Antenna Mast } \\
\text { Height }\end{array}$ & $\begin{array}{l}\text { Line Of Site Elevation at the Receiver (Or } \\
\text { Receiver Antenna Elevation) }\end{array}$ \\
\hline Path Inclination $(\varepsilon p)>0$ & $51.816 \mathrm{~m}$ & $36.712 \mathrm{~m}$ & $88.528 \mathrm{~m}$ \\
Path Inclination $(\varepsilon p)=0$ & $51.816 \mathrm{~m}$ & $36.712 \mathrm{~m}$ & $88.528 \mathrm{~m}$ \\
\hline
\end{tabular}

In table 3 , is can be seen that for Path Inclination $(\varepsilon p)=0$ antenna mast height of $36.712 \mathrm{~m}$ is required at the transmitter and at the receiver. However, for Path Inclination $(\varepsilon p)>0$ antenna mast height of $19.367 \mathrm{~m}$ is required at the transmitter and antenna mast height of $36.712 \mathrm{~m}$ is required at the receiver.

\section{Conclusion}

The approach for generating and plotting the path profile data for terrestrial line of site microwave link in presented. Sample path profile data set for a C-band link at $6 \mathrm{GHz}$ is generated and plotted for two cases, when the path inclination is equal to zero and when the path inclination is greater than zero. The signal path (or link) elevation profile (that is, elevation and distance) are obtained using Geocontext Online Elevation software. With the path profile data and graph plots, the minimum antenna elevation and the minimum antenna mast heights for effective line of site installation are determined. Also, the critical location where the line of site condition can easily be violated is also determined. The path profile tool presented in this paper is very useful for wireless network designers.

\section{References}

[1] Okorogu, V. N., Onoh, G. N., Onwujei, A. I., \& Oluka, E. C. (2012) A Technique for Planning Microwave and Cellular Path Profile in the Tropics and Determination of Antenna Tower Heights (A Study of Onitsha/Nnewi Axis of Anambra State, Nigeria). International Journal of Engineering Science and Innovative Technology (IJESIT) Volume 1, Issue 2, November 2012.
[2] Hansryd, J., Edstam, J., Olsson, B. E., \& Larsson, C. (2013). Non-line-of-sight microwave backhaul for small cells. Ericsson Review, 22.

[3] Matheson, R., \& Morris, A. C. (2012). The technical basis for spectrum rights: Policies to enhance market efficiency. Telecommunications Policy, 36(9), 783-792.

[4] Burrell, J. (2003). Disruptive effects of electromagnetic interference on communication and electronic systems (Doctoral. dissertation, George Mason University).

[5] Cordeiro, C., Gossain, H., Ashok, R., \& Agrawal, D. P. (2003, May). The last mile: Wireless technologies for broadband and home networks. In Center for Distributed and Mobile Computing, University of Cincinnati, Cincinnati, $\mathrm{OH}$. Presented at 21st Brazilian symposium on computer networks (SBRC 2003), Natal, Brazil.

[6] Hassan, A. K. (2011). Automated Microwave Antenna Alignment of Base Transceiver Station (Doctoral dissertation, Karlstad University).

[7] Series, M. (2011). Maritime broadband wireless mesh networks.

[8] de Sousa Nunes, T. M. (2012). Microwave radio link between two endpoints.

[9] Arzubi, A. A., Castro Lechtaler, A., Foti, A., Fusario, R., García Garino, C., \& García Guibout, J. (2010). Design of a Trans-Horizon radio link for ultra high and super high frequencies. In XVI Congreso Argentino de Ciencias de la Computación.

[10] Smith, D. R. (2012). Digital transmission systems. Springer Science \& Business Media. 
[11] Alcatel-Lucent (2012) Microwave System Path Survey Report. Technical report.

[12] Hufford, G. A., Longley, A. G., \& Kissick, W. A. (1982). A guide to the use of the ITS irregular terrain model in the area prediction mode. US Department of Commerce, National Telecommunications and Information Administration.

[13] Standard, F. (1996). Telecommunications: Glossary of telecommunication terms. Retrieved January, 15(2004), 69-72.
[14] Sharma, P. K., \& Singh, R. K. (2012). Cell coverage area and link budget calculations in GSM system. International Journal of Modern Engineering Research (IJMER) vol, 2, 170-176.

[15] Mahato, S. B. (2007). Performance Evaluation of Six-Sectored Configuration in Hexagonal WCDMA (UMTS) Cellular Network Layout.

[16] Geocontext Online Elevation software available at http://www.geocontext.org/publ/2010/04/profiler/en/ Accessed on July 1o 2016. 